\title{
Building a Geodatabase for Parcel and Cadaster Mapping and Add-Ins Development: A Case Study for Defense Housing Authority (DHA), Lahore, Pakistan
}

\author{
Mamoon Ur Rasheed, Sajid Rashid Ahmad, Rashid Saleem \\ College of Earth and Environmental Sciences, University of the Punjab, Lahore, Pakistan \\ Email: mamoonurrasheed@gmail.com, sajidpu@yahoo.com, rashid.saleem.lhr@gmail.com
}

Received 24 October 2015; accepted 5 December 2015; published 8 December 2015

Copyright (C) 2015 by authors and Scientific Research Publishing Inc.

This work is licensed under the Creative Commons Attribution International License (CC BY). http://creativecommons.org/licenses/by/4.0/

(c) (i) Open Access

\section{Abstract}

This paper presents a systematic view of most up-to-date tools, technologies and techniques which is appropriate not only for effective decision making, but also helpful for competent administration to provide efficient resolution for spatial troubles of Khasra and Parcel management. Different Data collection techniques have been applied on different data sources. Worldview II of 0.5 resolution image, scanned Master Plan and Cadastral/Khasra Maps was used for development of geodatabase for spatial and non-spatial entities using ArcGIS 10.2. Multiple processing on Satellite Imagery using ERDAS Imagine was performed like Image enhancement, Mosaicking and Color Balancing, Image Geo-referencing and Raster Cataloging. Development of Customize Graphical User Interface (GUI) for DHA's officials and administrator makes efficient decision in society matters. This is the first spatial GUI, for DHA to plan and maintain society's activities efficiently, in the form of ArcMap Add-Ins. These Add-Ins are written in C\#.Net using ArcObjects APIs within MSVS 2012.

\section{Keywords}

Khasra, Parcel, ArcMap, Add-Ins, ArcObjects, Geodatabase

\section{Introduction}

Over the previous spans, bulky volumes of digital spatial data have been shaped using geographic information system (GIS), image processing systems and software. Computer-aided design (CAD) also plays a vital role for data preparation [1]. Accurate and standard spatial data development is most important in Geospatial System 
Development. Such data are useful in many applications and situations like urban management, disaster management, etc. It is also beneficial in any spatial analysis (buffer, proximity, etc.) and spatial exhibiting techniques such as SDSS (Spatial Decision Support Systems), operations exploration, risk investigation, and artifi$\mathrm{cial} / \mathrm{mock}$ intelligence-expert schemes.

Urban and Regional Planning uses a geographic information system (GIS) as a Spatial Decision Support System (SDSS). It also offers highly evaluated map yields to decision makers (DM). Under real wildfire situations, GIS map products are very effective resources that include composed and examined information and outcomes envisioned to enable interpretation/clarification of the situation [2]. Under the "Automation of DHA Study", it is envisioned that GIS will provide the essential mapping interface and spatial analysis to facilitate DHA officials as system end users to carry out their desired spatial analysis and urban planning decisions.

As known, a GIS application can project different spatial data on different layers. Integrating different map layers into an urban tree management project improves insight for decision making [3]. The uses of GIS on urban applications are, not surprisingly, many and varied and helpful to provide excellent output to decision makers because geographic information systems are software systems used to capture, store, manage, analyze and display geospatial data sources [4]. GIS based management database is created to manage the spatial data and attribute data. With the help of GIS system, it is easy to handle plot data which are continuing changing after six months or a year. Plot information retrieval is fast and easy to manage. Other than the human management, it is also a tool of immoveable property and asset management. It does not only give better understandings of building infrastructure but also give a platform for helping the authorities to take progressive decisions based on complex analysis in short time period by using modern technologies. Goal of this study is to not only clear our understandings about GIS capabilities but also a significance role to provide platform for knowing about mapping techniques and Add-Ins development.

In this study, we are going to discuss the complete phases of Geo-database development and user friendly interface in ArcMap using C\#.Net Add-Ins for users to perform spatial queries to visualize, analyze and take required decision. Users are also able to manipulate the data by conducting complex spatial and non-spatial querying and searching.

\section{Study Area}

Defense Housing Authority (DHA) has a great importance for this country. DHA is located in Lahore, Punjab, Pakistan. It is established in March 19, 1975. It is 516.8 acres (64 square km) area. It has beautiful landscape.

The Study area includes area administrated by DHA and within the adjacent phase, which is around $116.5 \mathrm{Sq}$ $\mathrm{km}$. Out of this around 64Sq Km is administrated by DHA from Phase 1 - 9 (see Figure 1). The areas which lie on the periphery of DHA Phases along with the area that lie within the surrounding areas of DHA boundary also be included in this study scope with only major areas and localities parcels and Roads network. Both developed and under developed urban areas Phases from 1 - 9 define the boundary demarcations of the Project Area.

\section{Methodology}

\subsection{Data Collection}

Spatial information was obtained through hard copy map, scanned maps, ground survey and satellite imagery. Master plan maps, cadastral maps and their attribute information were acquired from Land Acquisition Branch-DHA as hard copy maps. There are total 9 and 43 master plan maps and Mouza maps respectively that spread over the project area. World View II of 0.5 resolution image was used for this project. To elimination of geo-metric errors of the image, at least 20 GCPs were collected using Dual Frequency GPS receiver Garmin Oregon 550 for every $60 \mathrm{sq}-\mathrm{km}$ area at road crossings or such prominent features that can be identified on the imagery (see step 1 of Figure 2).

\subsection{Data Processing}

Maps scanning, geo-referencing and mosaicking are applied on master plan maps and cadastral maps. The plot parcels, addresses, house numbering conventions and other details for land use were obtained through these master plan maps. Raw scanned files were spatially adjusted to overlay on the satellite image. ESRI ArcGIS software has been used for data processing [5]. An overall procedure of hard copy map transformation into a 


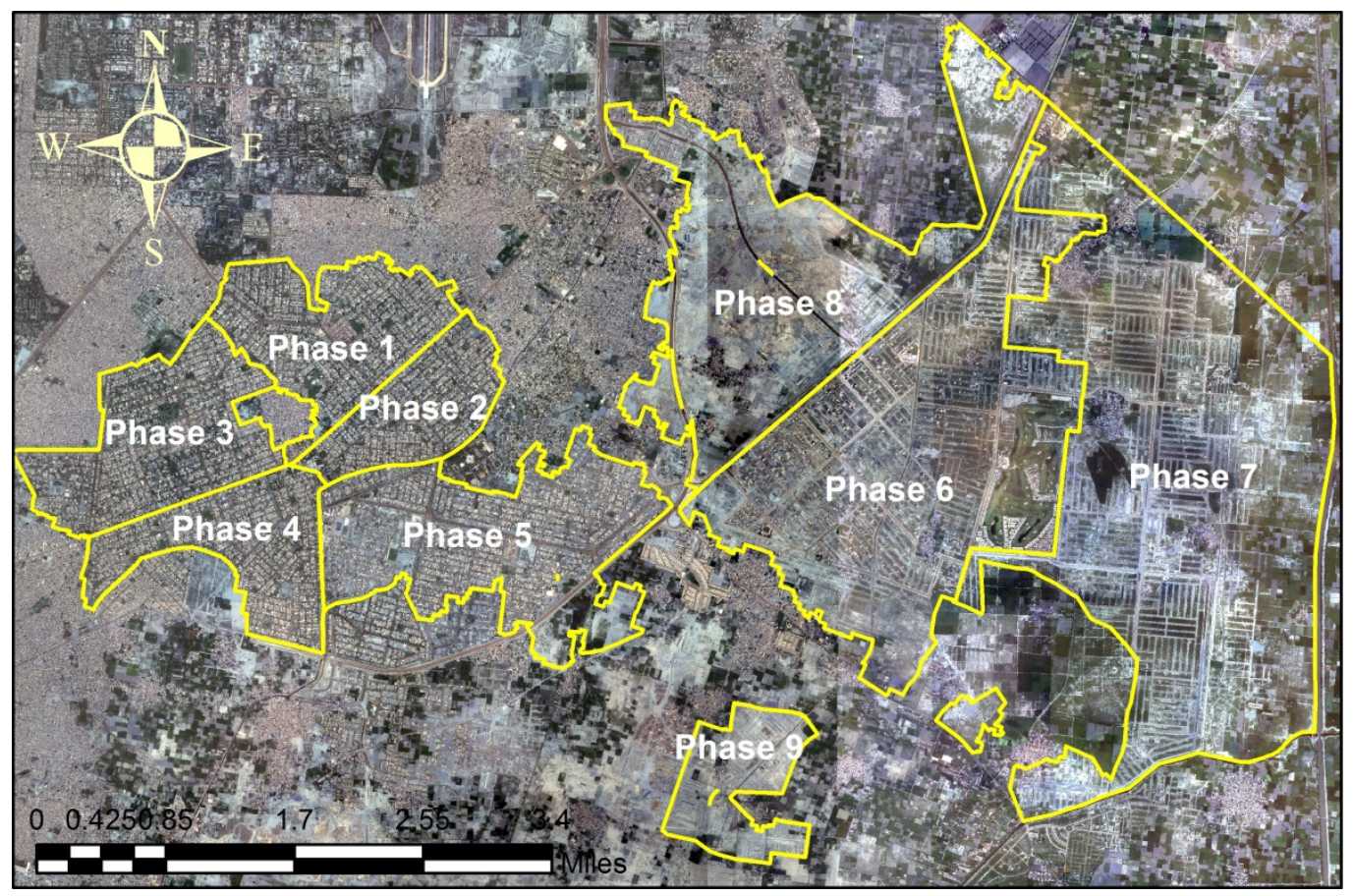

Figure 1. Study area.

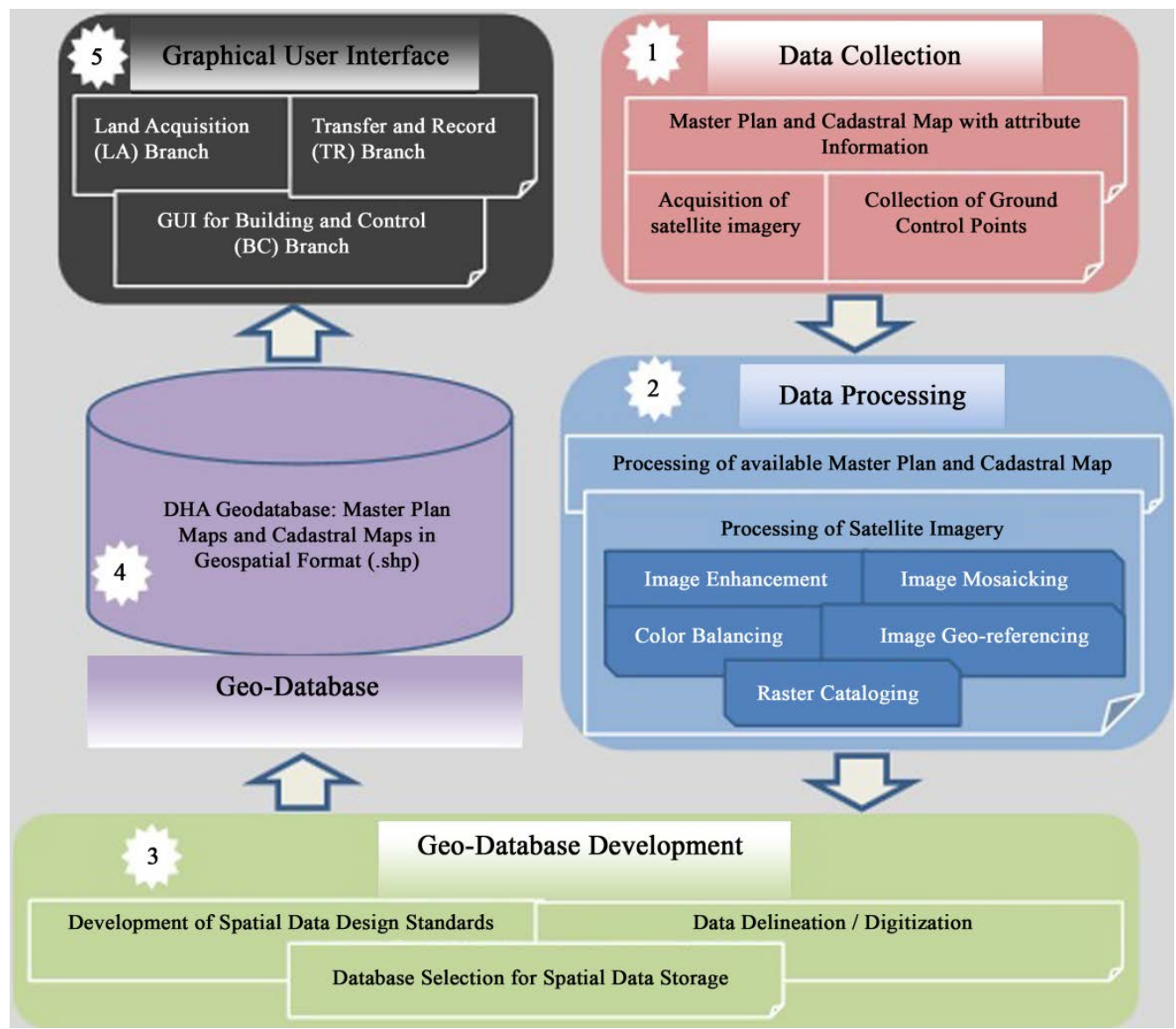

Figure 2. Methodology scheme for the DHA geodatabase development and its usage through arc map Add-Ins. 
mosaicked map is pictorially shown in Figure 3. Image enhancement, mosaicking, color balancing, image geo-referencing and raster cataloging are performed during processing of satellite imagery (see step 2 of Figure 2).

\subsection{Geodatabase Development}

Complete procedure of designing and building a geodatabase for managing master plan and cadastral maps (see step 3 of Figure 2).

\subsubsection{Spatial Data Design Principles}

It make possible for data distribution, integration and compatibility within the system.

\section{1) Layers and their fields naming}

They were defined using following six standards;

a) Names of the file based on alphanumeric characters (i.e. letters, numbers);

b) Letter should be at the start of the file name;

c) File full name completely in title case i.e. starts with a capital alphabet;

d) Except underscore, no spaces, dashes or special characters used;

e) File full names are based on 10 typeset/characters or fewer;

f) Universal short forms are used on the basis of requirement.

Sample filename of land use layer will be: "LU_(Feature Class)". shp

\section{2) Shapefiles development}

ArcInfoshapefiles (.shp) developed using decimal degrees have Double Precision. Double Precision, Fuzzy Tolerance 0.0001, Dangle Tolerance 0.0, Node Snap 0.0001 and Snap 0.5 tolerances are followed for all shapefiles datasets.

\section{3) Topology}

To create and maintain topology, the following quality standards are undertaken:

- Polygons must close properly that control the problem of overshoots/ undershoots;

- Pseudo nodes only exist where 1) a line close up with itself 2) only two linear features like lines cross 3) there is a modify in attribution beside a line 4) to preserve the shape and measurements of an arc;

- No duplication in linear (Lines), close (polygons) and points features. And annotation must be unique.

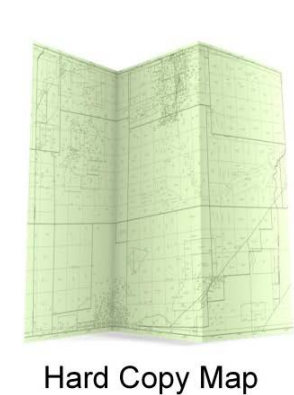

Hard Copy Map

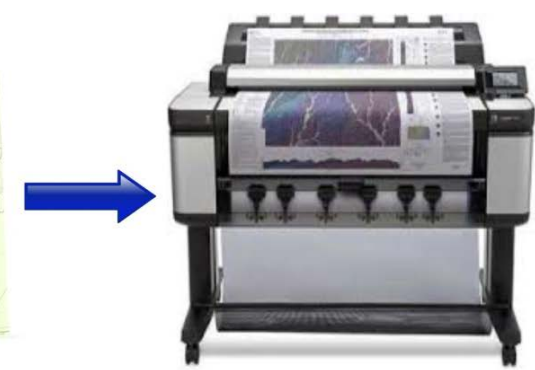

Scanning Process

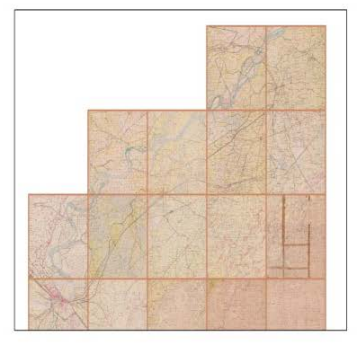

Mosaicking

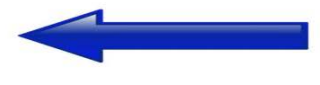

Geo-Referencing
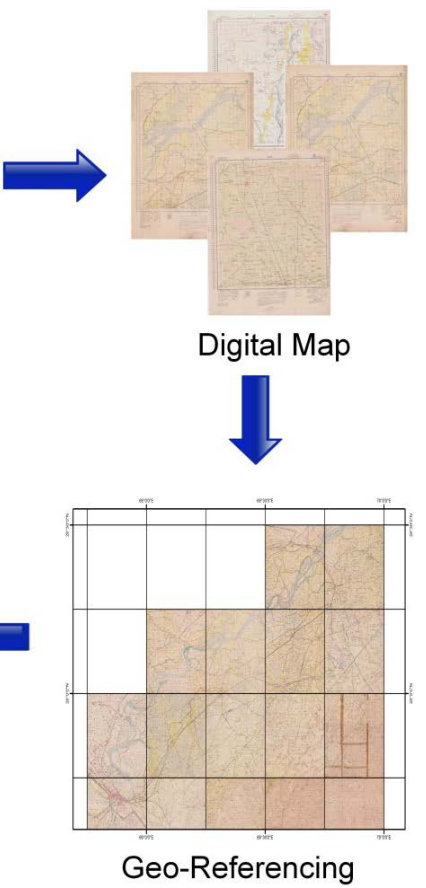

Digital Map

Figure 3. An overview of hard copy map transformation into a geo-referenced map. 
- Road layer must not break at bridge or other nodes; water stream channel (polyline) represent the entire length of the stream;

- Polygons should show only one label on each feature.

- No slivers polygons.

- Must not overlap in Polygons.

\subsubsection{Spatial Symbology}

As per international convention spatial symbologies are use. Figure 4 shows the sample spatial symbologies.

\subsubsection{Data Delineation/Digitization}

Nine layers were created-i.e. layers for Plots, Phase, Sector, Mouza, Khasra, Services, Facilities and Roads. Each layer has its own attribute table that contains the appropriate information according to requirement. During the digitization phase, map scale accuracy was set as 1:1500.

\subsubsection{Database for Spatial Data Storage}

In this study, a personal Geo-database is used to store spatial data that grip creating a Microsoft Access (.mdb) file on disk and row/record wise data is identified by OBJECTID but user can maintain their own IDs by adding new columns.

\begin{tabular}{|c|c|c|c|c|c|c|c|c|}
\hline \multirow{2}{*}{ Sr. No } & \multirow{2}{*}{ Category } & \multicolumn{2}{|c|}{ Point } & \multicolumn{2}{|c|}{ Line } & \multicolumn{2}{|c|}{ Polygon } & \multirow{2}{*}{ R-G-B Value } \\
\hline & & $\overline{\mathrm{DHA}}$ & Others & $\overline{\text { DHA }}$ & Others & $\overline{\text { DHA }}$ & Others & \\
\hline 1 & Residential & - & - & - & - & & - & $255,170,45$ \\
\hline 2 & Commercial & - & - & - & - & & - & $0,112,192$ \\
\hline 3 & Hospital & & & - & - & & - & $121,220,255$ \\
\hline 4 & Restaurants & & & - & - & & - & $0,112,192$ \\
\hline 5 & $\begin{array}{l}\text { Schools/ } \\
\text { colleges }\end{array}$ & & & - & - & & - & $121,220,255$ \\
\hline 6 & $\begin{array}{l}\text { Petrol/CNG } \\
\text { Pumps }\end{array}$ & & & - & - & & - & $121,220,255$ \\
\hline 7 & DHA Offices & & - & - & - & & - & $121,220,255$ \\
\hline 8 & $\begin{array}{c}\text { DHA Reserve } \\
\text { Area }\end{array}$ & & - & - & - & & - & - \\
\hline 9 & Police Stations & & - & - & - & & - & $121,220,255$ \\
\hline 10 & Rescue 1122 & & - & - & - & & - & $121,220,255$ \\
\hline 11 & Check posts & & - & - & - & - & - & - \\
\hline 12 & Bus Terminals & - & 7 & - & - & & - & $121,220,255$ \\
\hline
\end{tabular}

Figure 4. Sample spatial symbology. 


\section{Development of Customize Graphical User Interface (GUI)}

In this study, Geo-Database and ArcMap Add-Ins development are made for automate the DHA spatial work. According to user access rights and number of branches, multiple Add-Ins are developed using C\# Dot Net (C\#.Net). There are mainly two types of user. Query user having the rights to perform the spatial and attribute queries using Add-Ins to view sensitive information of the database. Land Ownership and Membership details and DHA Reserve areas etc. are important information to be available to only DHA Directors and above officers. Power user does not have the right to alter the database. Administrator has right to completely access, modify and change the database.

\section{Add-Ins Development}

According to three branches, three Add-Ins are developed using C\#.Net and ArcObjects SDK in Microsoft Visual Studio (MSVS) 2012. There are many types of Add-Ins available for ArcGIS when using the wizard. As per requirement, Button type Add-Ins builds. Each branch has their own spatial queries those are logically grouped. Table 1 shows the number of queries and their number of logical groups. Last column shows the branch wise layers name those are participated in queries.

Custom forms are developed to show the implementation of all 3 branches. These forms open from ArcMap 10.2. Each form has Search Criteria and Selection tabs. First and second tab shows the logical grouping of queries and searching filters of selected query (from first tab) respectively. Figure 5 shows the logical groups of land acquisition branch's queries.

Table 1. Branch wise no. of logical groups of queries and layers name those used during query.

\begin{tabular}{lcccl}
\hline \multicolumn{1}{c}{ Branch Name } & User Type & $\begin{array}{c}\text { No of } \\
\text { Queries }\end{array}$ & $\begin{array}{c}\text { No of } \\
\text { Logical Group }\end{array}$ & \multicolumn{1}{c}{ Layer Name Use in MXD } \\
\hline Building and Control (BC) & Query User & 11 & 4 & Plots, Phase, Sector, Mouza, Khasra, Services, Facilities, Roads \\
Land Acquisition (LA) & Query User & 15 & 5 & Plots, Phase, Sector, Mouza, Khasra \\
Transfer and Record (TR) & Query User & 12 & 7 & Plots, Phase, Sector, Mouza, Khasra, Roads \\
\hline
\end{tabular}

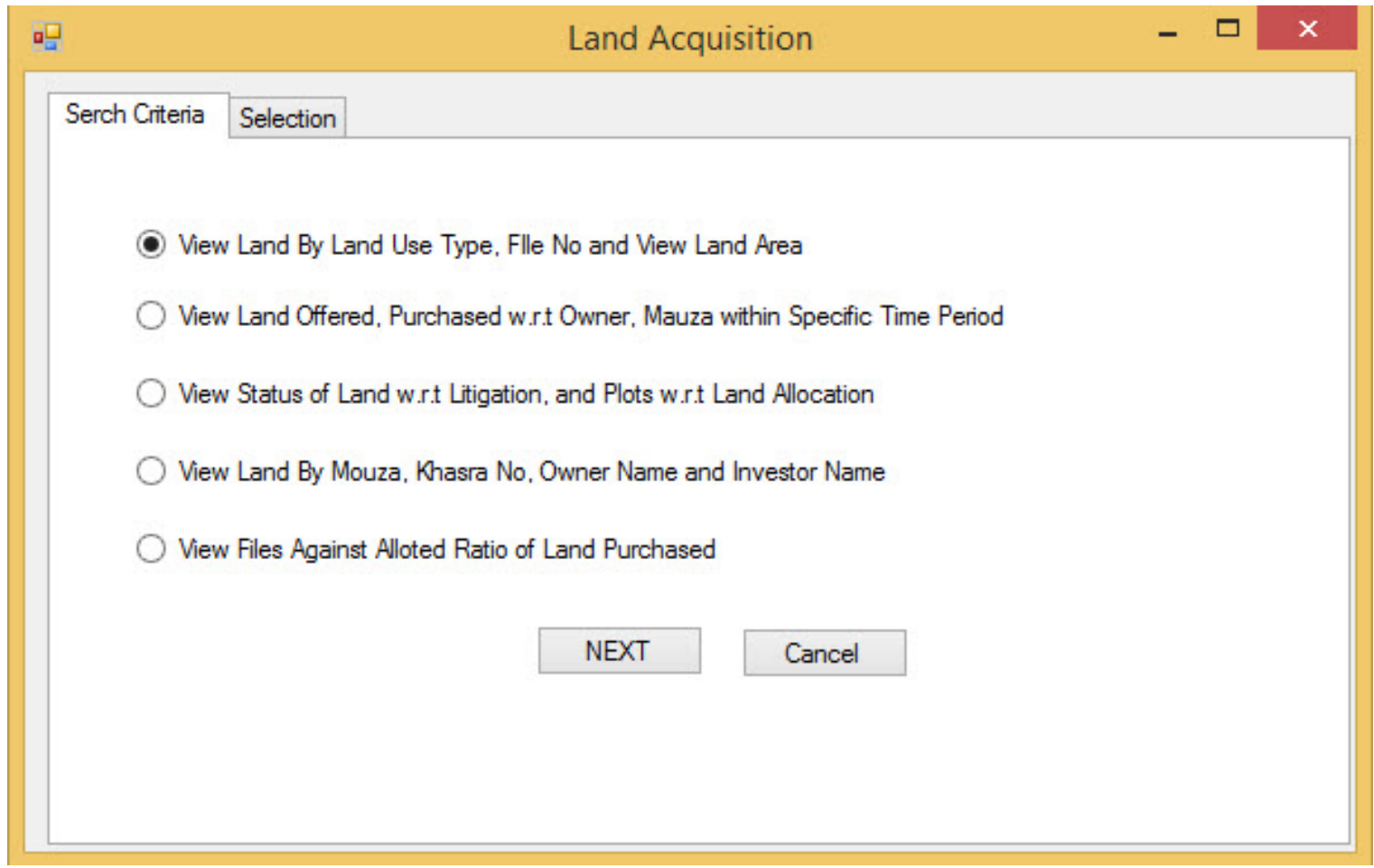

Figure 5. Logical groups of land acquisition branch queries. 


\section{Results}

Spatial data that were planned and developed is composed by six different spatial data layers. These spatial layers play vital role for the building of geodatabase as well as for spatial queries-spatial queries are always base on spatial data [6]. The spatial data that have been utilized for geodatabase development is shown in Figure 6. Main and important spatial layers in the geodatabase are Phase and Sector boundaries. This spatial datum is uses by

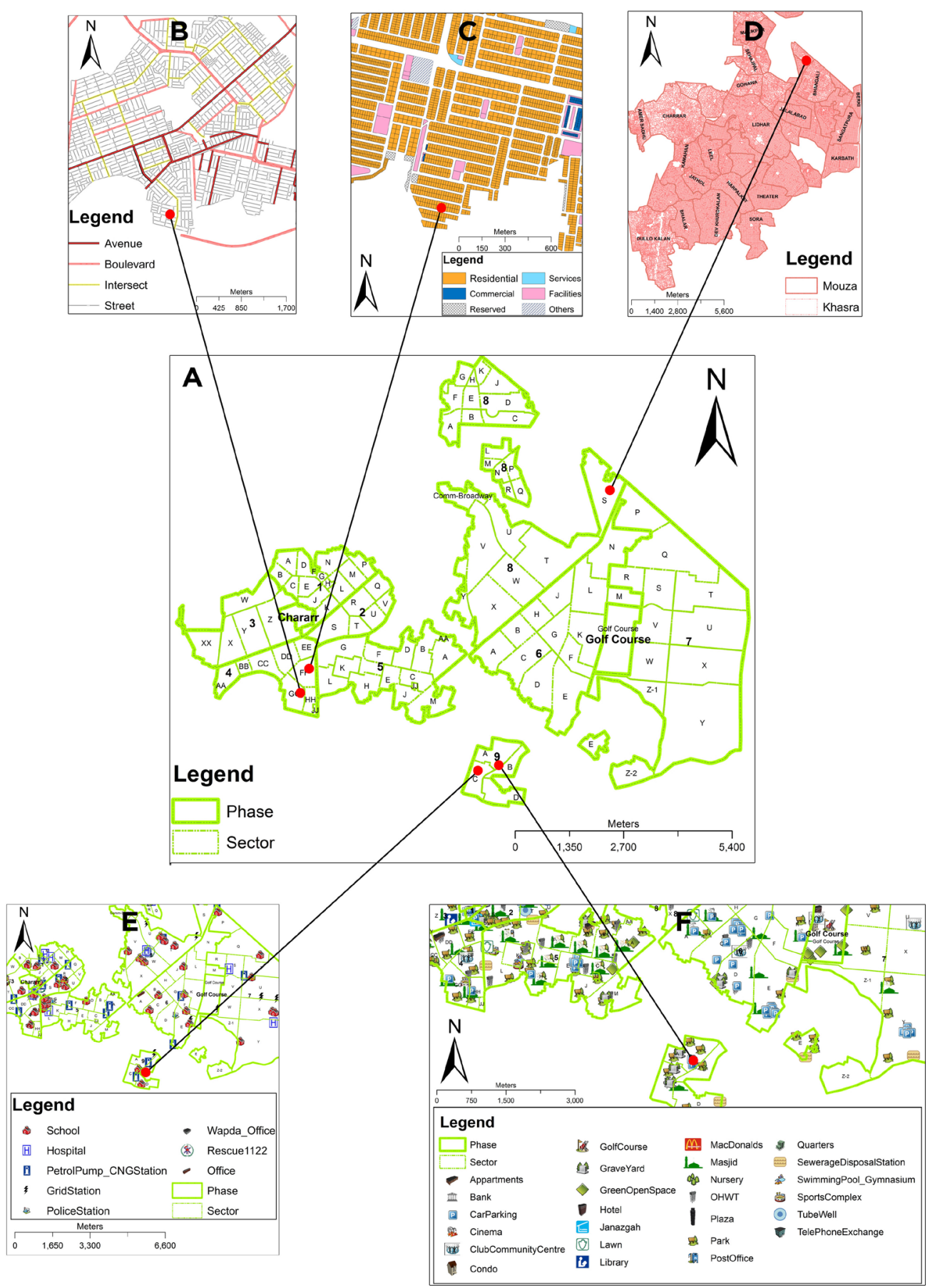

Figure 6. Spatial visualization of DHA's Geodatabase: (A) phase and Sector boundary of study area, (B) spatial view of different roads types, (C) six different types of plots, (D) example of khasra maps, (E) services in six different natures, (F) a view of multiple Facilities. 
the DHA's officials as a reference data for further spatial analysis (Figure 6(A)). Plots are elementary unit for the development of geodatabase of any urban area. In this study, six different types of plots (Residential, commercial, Reserved, services, facilities and others) are developed (Figure 6(B)). According to road width, four different types of Roads (Avenue, boulevard, Intersect and Street) are development and become part of the geodatabase for the whole study area (Figure 6(C)). Land Acquisition branch is directly interested for the use of Mouza maps for spatial analysis of specific land area within which there may be one or more settlements. Each Mouza has multiple Khasras (Figure 6(D)). For DHA, Services are the source for the revenue generation. Specifically, Building and Control branch of DHA is interested in Services spatial data for identification of new place for construction of new service. Currently there are eight different types of services (Schools, Hospitals, Petrol pumps/CNG Station, Grid Stations, Police, Wapda, Rescue and Office) are available (see Figure 6(E)). DHA is providing 26 different types of facilities for their residents (Figure 6(F)).

Two different tools are used to show the results of prebuilt queries on an appropriate layer. These tools are branch wise "Custom Add-In" and "Identify". In this study, Custom Tool is the substitute of the Arc Map default "Select by Attributes" Tool. Select by Attributes tool is complex to use for any non-GIS user as it requires expertise in Structure Query Language (SQL) to develop your own custom query for the selection of feature(s). Further, In ArcMap 10.2, Identify tool is given by default and has flexibility to change or improve the tool as per condition. In this study, we don't need to develop custom Identify tool because default Identify is full filling the current study requirement and very easy to use by any non-GIS user. Select the tool from the 'Tools' toolbar and click on that feature which attribute user wants to view. Automatically a dialog box will be open in the center of the screen with all attached attributes. In Figures 7-9, it shows that "Identify" tool is used to identify the feature information and properties after the selection of feature using Add-In. The Add-In finds the feature (i.e. Plot, Khasre, Road, etc.) by bringing it to the center of the screen and changing its color, so that it appears different from the rest. In Figure 7, user wants to know the plot number on the basis of owner name in Building and Control branch. After the selection of "search criteria" user control move to "Selection" tab by pressing next button. On "Selection" user selects the search filter(s) and press search button. Plot no 120 is highlighted. Then user opens the built-in "Identify" tool and click on the highlighted plot. All properties that are attached to the layer are displayed on the screen for further decisions.

\section{Conclusions and Suggestion}

In this paper, we present the development and implementation of geodatabase and customize interface in Arc-

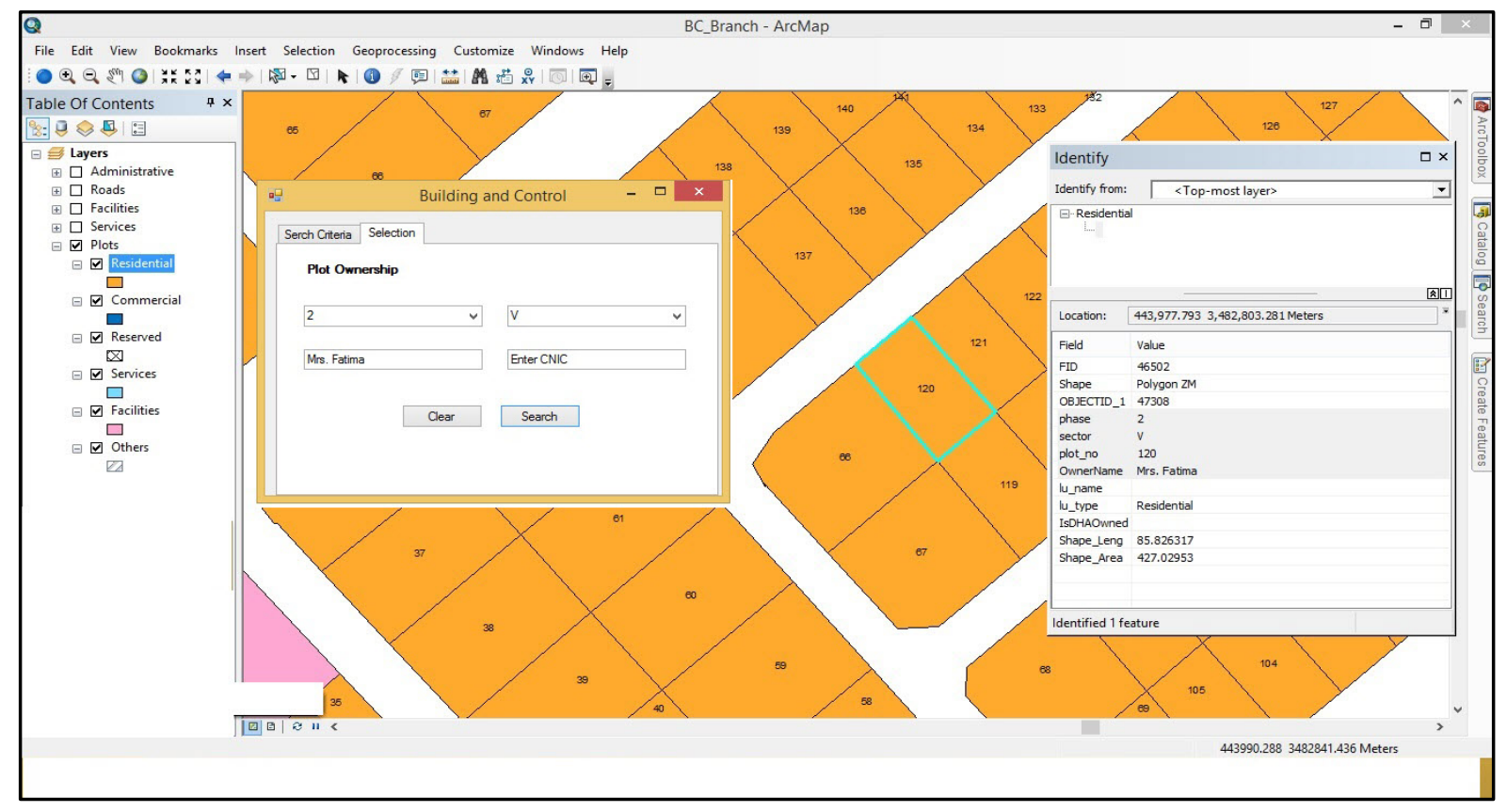

Figure 7. Query at building and control branch. 


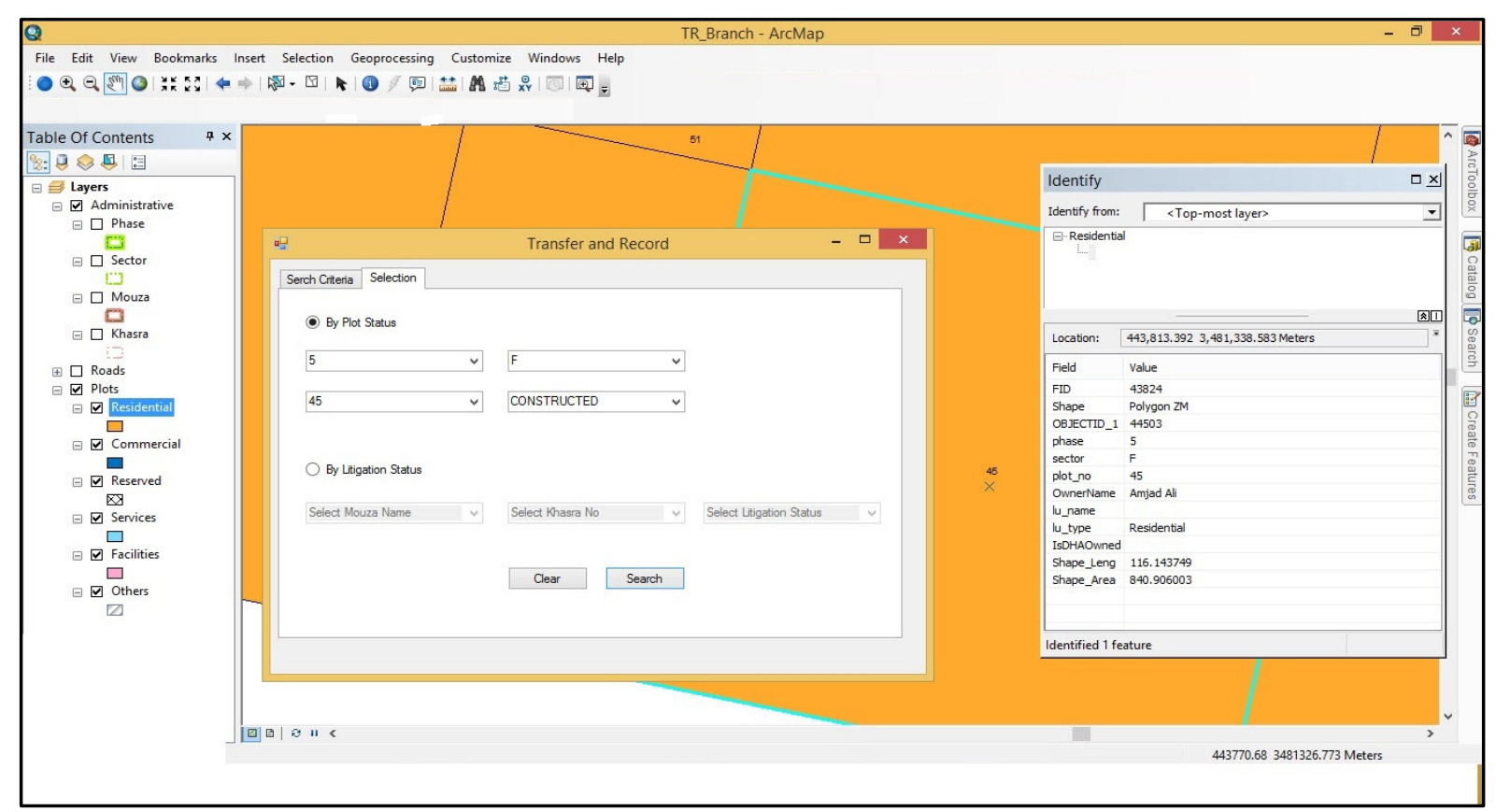

Figure 8. Query at transfer and record branch.

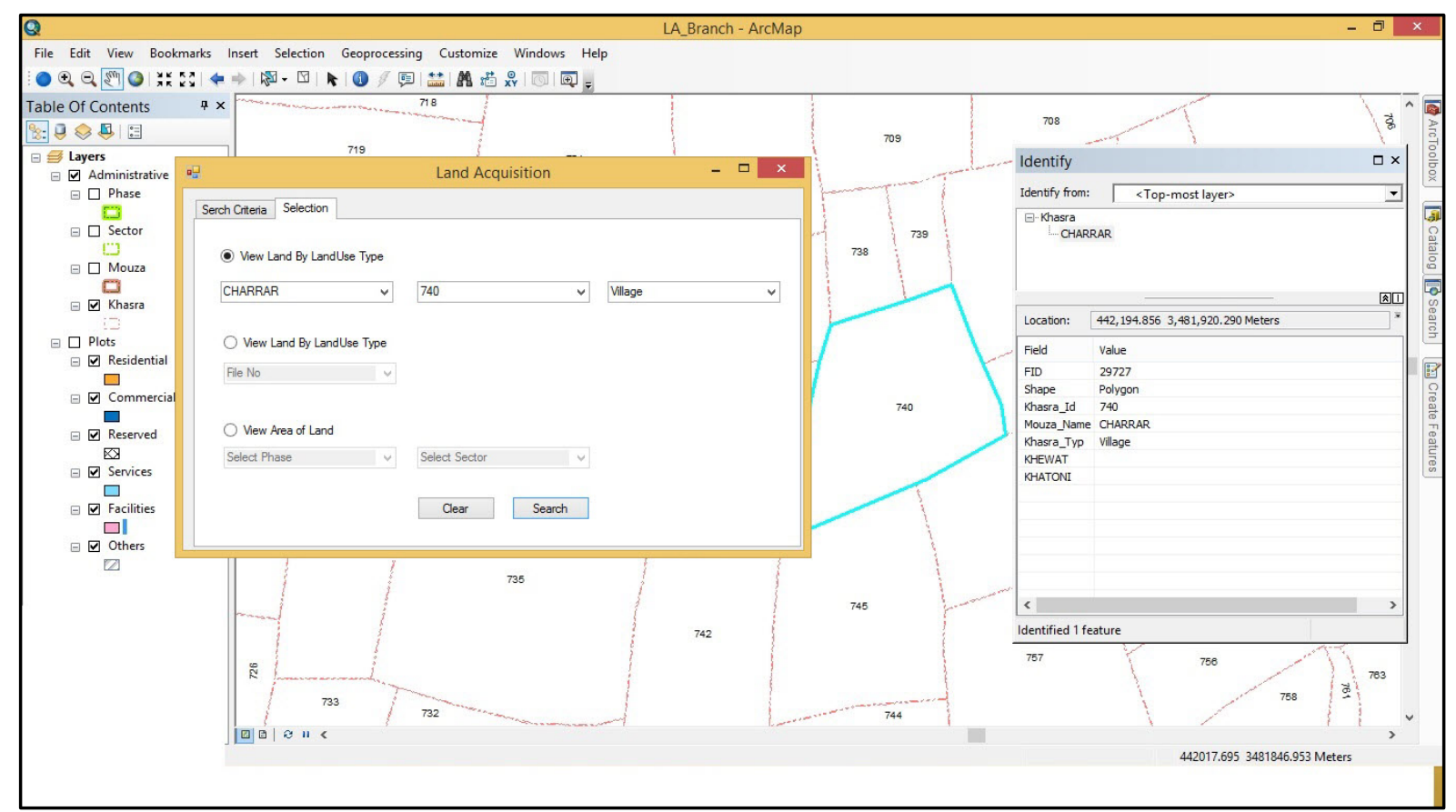

Figure 9. Query at land acquisition branch.

Map, commercially available software, for DHA and use personal geodatabase that involves creating Microsoft Access (.mdb) file as data storage. This is the first GIS repository for DHA to plan and maintain society's activities efficiently. Due to this effort, we provide systematic interface to DHA's officials and administrator to apply spatial functions on GIS layers, such as Plot-Parcel and Cadastral-Parcel search and Location wise queries with systematic way. And, it also provides the guide line for the GIS data developers.

There is a need to develop web-based GIS application to share such datasets and information. Decision-makers and administrators often have limited expertise in GIS and complex spatial analyses. Web GIS has the potential 
to share data, provide easy access for users with limited GIS knowledge, and assemble data and information customized for specific topics that support informed decision-making.

\section{Acknowledgements}

The authors appreciate the moral and technical support of DHA authorities who share the spatial and non-spatial data and business domain for the successful completion of the study.

\section{References}

[1] Huang, B. and Lin, H. (1999) GeoVR: A Web-Based Tool for Virtual Reality Presentation from 2D GIS Data. Computers \& Geosciences, 25, 1167-1175. http://dx.doi.org/10.1016/S0098-3004(99)00073-4

[2] Yi, C.J., Park, R.S., Murao, O. and Okamoto, E. (2012) Emergency Management: Building an O-D Ranking Model Using GIS Network Analysis. Journal of Disaster Research, 7, 793-802.

[3] Tasoulasa, E., Varrasa, G., Tsirogiannisa, I. and Myriounisa, C. (2013) Development of a GIS Application for Urban Forestry Management Planning. Procedia Technology, 8, 70-80. http://dx.doi.org/10.1016/j.protcy.2013.11.011

[4] Erden, T. and Coskun, M.Z. (2010) The Role of Geospatial Tools in Disaster Management Life Cycle. FIG Congress 2010 Facing the Challenges-Building the Capacity, Sydney, 11-16 April 2010, 10 p.

[5] ESRI (Environmental Systems Research Institute) (2013) GeoDatabases. ArcGIS Help 10.1 http://resources.arcgis.com/en/help/main/10.1/index.html\#/Types of geodatabases/003n00000007000000/

[6] Wunderlich, A.L. (2012) Automation in ArcGIS 10: Understanding Changes in Methods of Customization and Options for Migration of Legacy Code. “Digital Mapping Techniques “10-Workshop Proceedings” US Geological Survey OpenFile Report 2012-1171, 81-92. http://pubs.usgs.gov/of/2012/1171 